\title{
Coupled Analysis of Thorium-based Fuels in the High-Performance Light Water Reactor Fuel Assembly
}

\author{
Y. Pérez ${ }^{1}$, C. R. García ${ }^{1 *}$, F. L. Mena ${ }^{1}$, L. Castro ${ }^{2}$ \\ ${ }^{1}$ Instituto Superior de Tecnologías y Ciencias Aplicadas (InSTEC), Universidad de La Habana, \\ Ave. Salvador Allende No. 1110, Quinta de los Molinos, La Habana 10400, Cuba \\ ${ }^{2}$ Universidad Nacional Autónoma de México, Facultad de Ingeniería, Departamento de Sistemas Energéticos, \\ Paseo Cuauhnahuac 8532, Col. Progreso, 62550 Jiutepec, Morelos, México
}

\section{ARTICLE INFO}

\section{Article history:}

Received 23 July 2020

Received in revised form 13 April 2021

Accepted 14 April 2021

\section{Keywords:}

Supercritical water

HPLWR

CFD

Thorium-based fuels

Neutronic/thermal-hydraulic coupled analysis

\begin{abstract}
A B S T R A C T
One of the six selected concepts to be part of Generation IV nuclear reactors is the Supercritical Light Water Cooled Reactor. The High-Performance Light Water Reactor (HPLWR) is the European version and it is a very promising design. In recent years, interest in the study of thorium-based fuel cycles has been renewed and its possibilities for current LWRs have been evaluated. The use of thoriumbased fuels will be fundamental in the future sustainability of nuclear energy, since in addition to its abundance in nature, thorium has an important group of advantages. In this paper, performance of thorium-based fuels in the typical fuel assembly of the HPLWR reactor is evaluated, using a computational model based on CFD and Monte Carlo codes for the neutronic/thermal-hydraulic coupled analysis. The volumetric power density profiles, coolant temperature profiles, fuel temperature profiles and others are compared with those obtained for standard $\mathrm{UO}_{2}$ fuel. When the thorium-based fuels are used, the obtained infinite multiplication coefficients are smaller than the value obtained when $\mathrm{UO}_{2}$ is used, since the ${ }^{232} \mathrm{Th}$ isotope has a lower contribution to the multiplicative properties of the medium than ${ }^{238} \mathrm{U}$. As a result, a difference of approximately $12000 \mathrm{pcm}$ was observed. The results verified that the HPLWR is a thermal reactor with a hard spectrum. There are no notable changes in the neutron spectrum if the mass fraction of thorium is slightly varied. With coupled analysis, the potential benefits of the utilization of thorium-based fuels were verified. Moreover, a significant temperature decrease by $136 \mathrm{~K}$ on the center line of the fuel elements was observed. When the mass fraction of thorium increases in the oxides mixture, the weighted average temperature on the fuel elements decreases.
\end{abstract}

(C) 2021 Atom Indonesia. All rights reserved

\section{INTRODUCTION}

Among the concepts selected to be part of Generation IV nuclear reactors is the Supercritical Light Water Cooled Reactor (SCWR). This reactor type has technological, economic and sustainability characteristics that make it truly attractive. The High-Performance Light Water Reactor (HPLWR) is the European version of the SCWR [1].

The HPLWR is cooled by light water that reaches temperature and pressure values higher than those corresponding to its critical thermodynamic state $\left(374{ }^{\circ} \mathrm{C}, 22.1 \mathrm{MPa}\right)$. The coolant enters the

\footnotetext{
*Corresponding author.

E-mail address: carlosrgh2012@gmail.com

DOI: https://doi.org/10.17146/aij.2021.1081
}

reactor core with pressure of $25 \mathrm{MPa}$ and temperature of $280{ }^{\circ} \mathrm{C}$, reaching an average temperature of up to $510{ }^{\circ} \mathrm{C}$ at its outlet.

SCWRs have electricity production as their main objective, with a thermal cycle efficiency of around $44 \%$, which is one of the main advantages compared to current light water-cooled reactors (LWR). The LWRs have efficiency values in the range $32-36 \%$. Reduced construction costs due to the elimination of various components used in LWRs constitute another design advantage. The proposed original fuel for the SCWR concept is standard $\mathrm{UO}_{2}$, and both a fast and thermal neutron spectrum designs are possible.

A main characteristic of SCWRs is the large variation in the water thermophysical properties 
during its ascent through the reactor core. The changes produced in the properties of the coolant water and the moderator water generate variations in the energy and momentum transport, which in turn influences heat transfer and neutron moderation. Due to the strong interdependence between the axial heat flux profile and the axial water density profile, coupled neutronic/thermalhydraulic analysis is necessary to assess the safety parameters of the core of the SCWRs.

In [2] the use of uranium nitrate (UN) and uranium carbide (UC) as alternative fuels to $\mathrm{UO}_{2}$ was studied, in order to improve the neutronic and thermal-hydraulic performance of the HPLWR core. From the result of the studies, a lower temperature was obtained in the central line of the fuel elements, due to the higher thermal conductivity of the studied fuels. In addition, it was concluded that changes in porosity of proposed fuels have little influence on the maximum temperature values reached.

Thorium dioxide $\left(\mathrm{ThO}_{2}\right)$ is another so-called alternative nuclear fuel. In recent years, interest in the study of thorium-based fuel cycles has been renewed and its possibilities for current LWRs have been evaluated [3]. The use of thorium-based fuels will be fundamental in the future sustainability of nuclear energy, since in addition to its abundance in nature thorium has an important group of advantages.

The ${ }^{232} \mathrm{Th}$ presents a thermal neutron absorption cross section 3 times larger than that of ${ }^{238} \mathrm{U}$, which makes it a better fertile fuel and allows obtaining a higher conversion ratio in reactors with a thermal neutron spectrum. Among the characteristics of $\mathrm{ThO}_{2}$ are having higher melting temperature than $\mathrm{UO}_{2}(3651 \mathrm{~K}$ and $3120 \mathrm{~K}$, respectively), being chemically more stable, more resistant to irradiation, and having a better thermal conductivity, allowing higher burnup and power density values to be obtained in thorium-based fuels. On the other hand, thorium-based fuel cycles produce less long-lived nuclear waste such as plutonium and minor actinides (MA), which constitutes an environmental advantage [3].

Two configurations, homogeneous and heterogeneous, have been proposed so far for the use of thorium as alternative fuel. In the homogeneous configuration, the fuel used is a mixture of thorium and uranium oxides, with low enrichment of ${ }^{235} \mathrm{U}$. The heterogeneous configuration, meanwhile, uses the concept of seed and blanket, and usually separate the fuel as driver fuel and blanket fuel. The heterogeneous option is related with advanced nuclear fuel cycles using partitioning and transmutation of MA and plutonium isotopes. It will require post-irradiation seed fuel reprocessing before final disposal. In [4] several thorium-based fuel cycles were proposed, multi-stage fuel cycles with current thermal reactors were considered, using driver and blanket fuel assemblies. SCWR are not proposed.

The homogeneous configuration of thoriumbased fuels in SCWRs with a thermal neutron spectrum has been considered to avoid more heterogeneity than that produced by the presence of water boxes. However, with this setting, lower burnup values are achieved compared to heterogeneous configurations.

In [5] thorium-based fuels in SCWRs were studied. The results show that thorium-uranium dioxide fuels lead to smaller burnup values as compared to equivalent enriched uranium dioxide, but possess the advantage of smaller excess reactivity at initial load state. This can lead to savings in the use of burnable absorbers to balance the reactivity excess. SCWR, like boiling water reactor (BWR), does not use chemical shim for reactivity control during normal operation. Smaller fuel average temperature values were obtained for thorium-uranium dioxide fuels as compared to uranium dioxide fuel option.

In [6] a SCWR thorium-based hexagonal fuel assembly was researched. The fuel cycle proposed used thorium fuel with ${ }^{233} \mathrm{U}$ as fissile material. Oneand two-dimensional calculations were carried out to find the optimal assembly heterogeneous configuration. The goal was to come up with an assembly configuration which reached a conversion ratio higher than 1.0 for ${ }^{233} \mathrm{U}$, thus only the diminution of the ${ }^{232} \mathrm{Th}$ must be compensated. Additionally, the fuel temperature and power reactivity coefficients were calculated. Both are negative proving the inherent safety of the reactor.

The development of computer science has turned Computational Fluid Dynamics (CFD) into a powerful numerical calculation tool for the analysis of nuclear reactors. By using it, the thermalhydraulic behavior of nuclear reactor cores can be predicted with great accuracy. In this work, the performance of thorium-uranium dioxide based fuels $\left(\mathrm{UO}_{2}+\mathrm{ThO}_{2}\right)$, in the typical fuel assembly of the HPLWR reactor is evaluated, using a computational model based on CFD and Monte Carlo codes for the neutronic/thermal-hydraulic coupled analysis. The results are compared with those obtained for standard $\mathrm{UO}_{2}$ fuel.

An outline of the remainder of this paper follows. In the next section, the HPLWR reactor core main parameters and characteristics are described. Section 3 presents the CFD and Monte Carlo based computational model. In Section 4, the results of the neutronic/thermal-hydraulic coupled analysis are presented and discussed. Section 5 gives a number of concluding remarks. 


\section{High-Performance light water reactor characteristics}

In 2006, 12 organizations from 8 European countries joined a SCWR design project called High-Performance Light Water Reactor. In Fig. 1 its scheme is shown, the coolant enters the core with pressure of $25 \mathrm{MPa}$ and temperature of around $280{ }^{\circ} \mathrm{C}$ and reaches an outlet average temperature of approximately $500{ }^{\circ} \mathrm{C}$. The planned electrical power in the design is $1000 \mathrm{MWe}$. The net thermodynamic efficiency of the plant is close to $44 \%$, and the reactor core has a thermal neutron spectrum. The main design data is given in Table 1 [7].

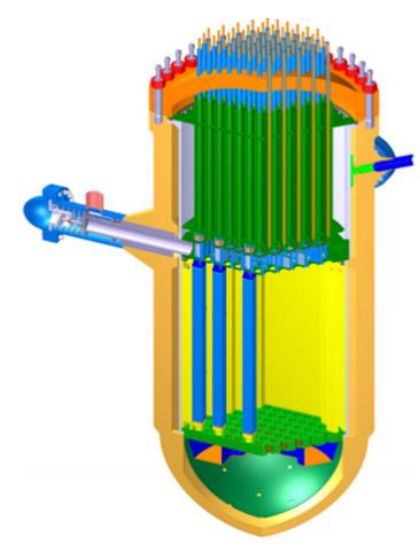

Fig. 1. One-pass core design concept of the HPLWR.

Table 1. Main design parameters of the HPLWR.

\begin{tabular}{lr}
\hline \multicolumn{1}{c}{ Parameters } & Values \\
\hline Electrical power $(\mathrm{MWe})$ & 1000 \\
Thermal power $(\mathrm{MWt})$ & 2075 \\
Pressure $(\mathrm{MPa})$ & 25 \\
Core mass flow $(\mathrm{kg} / \mathrm{s})$ & 1160 \\
Coolant inlet temperature $\left({ }^{\circ} \mathrm{C}\right)$ & 280 \\
Coolant outlet temperature $\left({ }^{\circ} \mathrm{C}\right)$ & 500 \\
Number of fuel assemblies & 88 \\
Full number of fuel rods & 31680 \\
Core height $(\mathrm{m})$ & 4.2 \\
Vessel height $(\mathrm{m})$ & 13 \\
Vessel external diameter $(\mathrm{m})$ & 4 \\
\hline
\end{tabular}

The layout of HPLWR fuel assembly is shown in Fig. 2. The square geometry fuel assembly features 40 fuel rods and a moderator box in the center. The studies carried out showed that, with this arrangement of the fuel rods, the highest power density was obtained with the least possible ${ }^{235} \mathrm{U}$ fuel enrichment. In addition, a flatter radial neutron flux distribution compared to other designs was obtained.

In this design, the moderator-to-fuel ratio is similar to that obtained in standard PWRs, and there is a small ratio of structural material to combustible material, which minimizes neutron absorption.

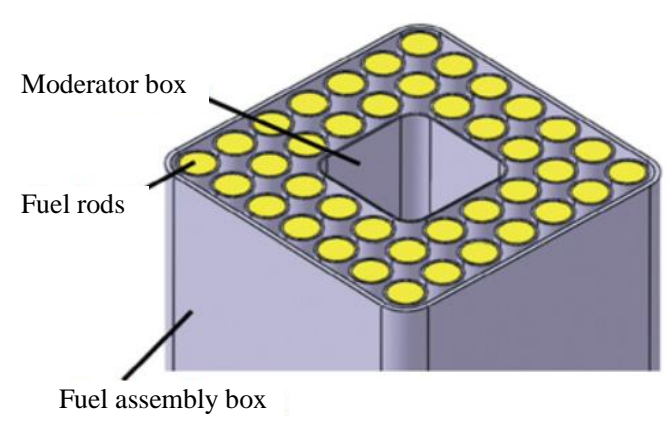

Fig. 2. Layout HPLWR fuel assembly.

In the HPLWR core, there is an additional amount of water to the coolant that works as neutron moderator only. Taking into account the path of water in the fuel assembly, the HPLWR core designs can be classified into single-pass, two-step, and three-step designs.

In this work, the simplest configuration, which is the one-step configuration, was studied. In it, approximately $25 \%$ of the feed water is directed to the vessel upper plenum, from where it descends to the lower plenum as external moderator through the spaces between the boxes of the fuel assemblies and it also flows down as an interior moderator through the interior moderator box. The remaining $75 \%$ descends through the space between the vessel walls and the reactor core to the lower plenum, where it mixes with the water with moderating functions and rises as a coolant. Table 2 gives the main data of typical HPLWR fuel assembly used in the simulation [8].

Table 2. HPLWR's fuel assembly geometric data.

\begin{tabular}{lc}
\hline \multicolumn{1}{c}{ Parameters } & Values (mm) \\
\hline Outer box width & 67.2 \\
Outer box wall thickness & 1 \\
Inside radius of the outer box corner & 5 \\
curvature & 10 \\
Gap between outer boxes & 26.8 \\
Inner box width & 0.3 \\
Inner box wall thickness & 4.2 \\
Outside radius of the inner box corner & 4200 \\
curvature & 8 \\
Core active height & 0.5 \\
Fuel rod outer diameter & 6.7 \\
Cladding thickness & 1 \\
Fuel pellets diameter & 1.2 \\
Gap between fuel rod and box wall & \\
Pitch lattice &
\end{tabular}

CFD-Based computational model for neutronic/thermal-hydraulic coupled analysis

A three-dimensional computational model based on CFD and the Monte Carlo method for 
neutronic/thermal-hydraulic coupled calculation of one eighth of the typical HPLWR fuel assembly using fuel mixtures of $\mathrm{UO}_{2}+\mathrm{ThO}_{2}$ was developed Fig. 3 shows the layout of the eighth of the fuel assembly considered [8].

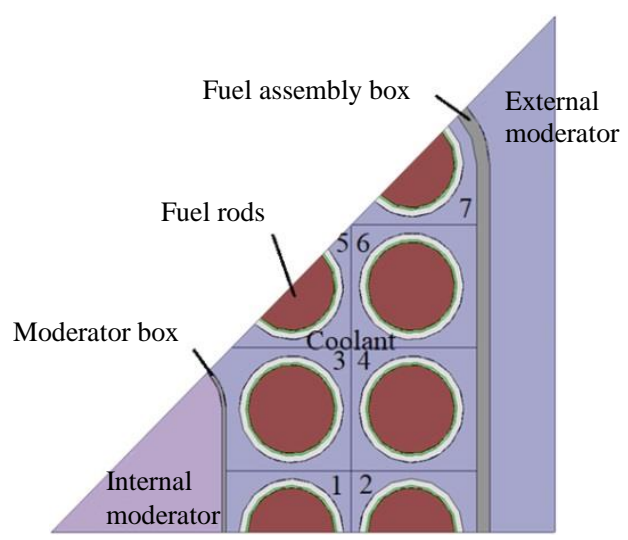

Fig. 3. Layout of one-eighth of the HPLWR fuel assembly.

An MCNP6 [9] model of the HPLWR fuel assembly was built for the neutronic calculations. The main objective of the neutronic calculation is to obtain the fuel assembly heat flow axial distribution. To build the geometrical model description of fuel assembly with MCNP6, the fuel rods, the cooling water and the exterior and interior moderators were divided into 21 cells of $200 \mathrm{~mm}$ height in the axial direction. The temperature and density of the materials are assumed to be constant in each cell. Reflective boundary conditions were imposed on the radial limits of the considered fuel assembly. For this reason, neutron leakage in the radial direction is not considered. To consider the presence of the upper and lower plenums, cells $200 \mathrm{~mm}$ high in the axial direction were defined. The number of particles considered in one cycle was 50,000, the number of inactive cycles was 50 and the total number of cycles was 1000 .

CFD is based on the so-called governing equations of fluid motion. These equations represent mathematical statements of the laws of conservation of physics, specifically of the law of conservation of mass, Newton's second law and the first law of thermodynamics. The governing equations that define the physical characteristics of the flow are second order partial differential equations that, due to their high degree of complexity, must be solved numerically.

Due to the strong interdependence between the axial heat flux profile and the axial water density profile, it is essential to perform a neutronic/thermalhydraulic coupled calculation to describe the safety features of HPLWR fuel assembly. The threedimensional coupled calculation of the typical HPLWR fuel assembly was performed using the MCNP6 code for neutronic calculation with the ENDF/62MT cross section library and the CFD code ANSYS-CFX 18.1 [10] for thermal-hydraulic calculation.

The energy profile obtained with neutronic calculation in the first iteration is implemented in the CFD thermal-hydraulic code as a volumetric heat flux source in the fuel elements. A steady-state calculation is made and new temperature and density profile of the water and temperature profile of the fuel rods are obtained. These temperature and axial density distributions are transferred back to the neutronic code to recalculate the energy distribution generated in the fuel rods. To reach the convergence of the calculation, it required that the maximum relative deviation is less than $1 \%$ between the values of the energy profile from two consecutive iterations [7].

The goal of the neutronic/thermal-hydraulic coupled is to describe the behavior of the HPLWR typical fuel assembly in steady state at the beginning of the cycle (BOC), using mixtures of $\mathrm{UO}_{2}+\mathrm{ThO}_{2}$.

In the homogeneous mixtures of thorium and uranium oxides studied, the initial fissile material is ${ }^{235} \mathrm{U}$. Table 3 shows the proportions used. In both cases analyzed, the mixture of thorium and uranium oxides was enriched to $5 \%$ by weight of ${ }^{235} \mathrm{U}$, except for rod 7, which was enriched to $4 \%$ to counteract the excess of neutron moderation that occurs in the cell [7].

The values of the mass fractions of ${ }^{235} \mathrm{U}$ in the $\mathrm{UO}_{2}$ of the $\mathrm{UO}_{2}+\mathrm{ThO}_{2}$ mixture were selected in such a way that the same initial mass of the fissile isotope is maintained as when using the standard $\mathrm{UO}_{2}$ fuel.

Table 3: $\mathrm{UO}_{2}+\mathrm{ThO}_{2}$ fuel compositions.

\begin{tabular}{|c|c|c|c|}
\hline Case & Fuel & $\begin{array}{l}{ }^{235} \mathrm{U} \text { mass fraction } \\
\text { in } \mathrm{UO}_{2} .\end{array}$ & $\begin{array}{c}{ }^{235} \mathrm{U} \text { mass fraction in } \\
\mathrm{UO}_{2}+\mathrm{ThO}_{2}\end{array}$ \\
\hline 1 & $(50 \%$ Th- 5 & $\begin{array}{c}10 \%(\operatorname{rods} 1-6) \\
8 \%(\operatorname{rod} 7)\end{array}$ & $\begin{array}{c}5 \%(\operatorname{rods} 1-6) \\
4 \%(\operatorname{rod} 7)\end{array}$ \\
\hline 2 & $(60 \% \mathrm{Th}-40 \% \mathrm{U}) \mathrm{O}_{2}$ & $\begin{array}{c}13 \%(\operatorname{rods} 1-6), \\
10 \%(\operatorname{rod} 7)\end{array}$ & $\begin{array}{c}5 \%(\operatorname{rods} 1-6) \\
4 \%(\operatorname{rod} 7)\end{array}$ \\
\hline
\end{tabular}

The main boundary conditions used in the thermal-hydraulic calculations are summarized in Table 4. The properties of the water were taken from the International Association for Water Properties [11].

Table 4: Thermal-hydraulic calculation main boundary conditions.

\begin{tabular}{lc}
\hline \multicolumn{1}{c}{ Parameters } & Values \\
\hline System pressure $(\mathrm{MPa})$ & 25 \\
Moderator water inlet temperature $\left({ }^{\circ} \mathrm{C}\right)$ & 280 \\
Coolant water inlet temperature & Equation 1 \\
Mass flow of coolant $(\mathrm{kg} / \mathrm{s})$ & 0.167 \\
Internal moderator mass flow $(\mathrm{kg} / \mathrm{s})$ & 0.01336 \\
External moderator mass flow $(\mathrm{kg} / \mathrm{s})$ & 0.02672 \\
\hline
\end{tabular}


To obtain the coolant inlet enthalpy $\left(h_{\text {TOT }}\right)$, an energy balance was applied at the boundary of the lower plenum in Eq. (1).

$$
h_{T O T}=\frac{\dot{m}_{M B} h_{M B}+\dot{m}_{A G} h_{A G}+\dot{m}_{D C} h_{D C}}{\dot{m}_{T O T}}\left[\frac{\mathrm{J}}{\mathrm{kg}}\right]
$$

where $\mathrm{h}$ is enthalpy, $\dot{m}$ is the mass flow, the subscript TOT stands for the coolant, MB represents the moderator box, AG represents assembly gap and DC represent the water flowing through the down-comer.

An axial volumetric density distribution of heat is considered for fuel rods. The equations describing the axial distribution of the average volumetric heat flux are obtained from the released energy values calculated with MCNP6.

The Total Energy model was used to calculate the water temperature (coolant and moderator) and the helium temperature, which includes the effects of the kinetic energy of the fluids. Moderator boxes, fuel cladding, and fuel rods are solid domains in stationary states, so the Thermal Energy model is used to consider heat transfer.

The SSG turbulence model was used. It considers a non-isotropic behavior of turbulence. The modeling of anisotropic turbulence, like supercritical water flow in the HPLWR fuel assembly is theoretically better made using Reynolds stress models. The SSG turbulence model uses wall functions for predicting the turbulence near the walls. With this approach, the region of the sub-layer affected by the viscosity is solved using empirical formulas to provide boundary conditions near the wall for the transport turbulence equations, saving computational resources [12].

However, it has been shown that there are no significant differences between the axial distributions of temperature and the average density profile of water calculated with the SST and SSG models, so the latter can be used if only the average behavior of the thermal-hydraulic parameters of the fuel assembly are wanted.

For the CFD simulation, a tri-dimensional computational mesh was built, formed by prismatic and hexahedral elements. A mesh sensitivity study was carried out to eliminate numerical errors due to the size and distribution of the mesh. The results were considered mesh independent when the maximum relative deviation values of coolant and fuel temperatures were approximately $2 \%$ between two consecutive simulations. Double numerical precision was used to reduce round-off errors. Robust and well-posed physics models were used that minimize model errors.
The main thermophysical properties of steel alloy SS316L used as fuel cladding depend on the temperature according to the following equations in Eqs. (2-4) [13].

$$
\begin{aligned}
& \rho_{S S 316 L}= \\
& 8084-0.4209 T-3.894 * 10^{-5} T^{2}\left[\frac{\mathrm{kg}}{\mathrm{m}^{3}}\right] \\
& c_{p_{S S 316 L}}=462+0.134 T \quad\left[\frac{\mathrm{J}}{\mathrm{kgK}}\right] \\
& \lambda_{S S 316 L}=9.248+0.01571 T \quad\left[\frac{\mathrm{W}}{\mathrm{mK}}\right]
\end{aligned}
$$

where $\rho_{S S 316 L}$ is the cladding density, $c_{p_{S S 316 L}}$ is the specific heat, $\lambda_{S S 316 L}$ is the thermal conductivity and $\mathrm{T}$ is the temperature in Kelvin.

The thermal conductivity of moderator boxes was considered like the thermal conductivity of zirconium $\left(\lambda_{b o x}=2.7 \mathrm{~W} / \mathrm{mK}\right)$. Density was considered equal to $7745.48 \mathrm{~kg} / \mathrm{m}^{3}$, while the specific heat depends on the temperature by equation 3.

The main parameters of helium were considered constant and were taken according to in Eq. (5) [10].

$$
\begin{aligned}
\rho_{H e} & =0.01742 \frac{\mathrm{kg}}{\mathrm{m}^{3}}, c_{p_{H e}}=5195 \frac{\mathrm{J}}{\mathrm{kgK}}, \\
\lambda_{H e} & =0.45944 \frac{\mathrm{W}}{\mathrm{mK}}
\end{aligned}
$$

The thorium-uranium dioxide fuel density varies with temperature according to the equation in Eq. (6).

$$
\begin{aligned}
& \rho_{(T h, U) O_{2}}=10.087-2.891 \cdot 10^{-4} T-6.354 \\
& 10^{-7} \alpha T+9.279 \cdot 10^{-3} \alpha+5.111 \cdot 10^{-6} \alpha^{2}
\end{aligned}
$$

$\rho_{(T h, U) O_{2}}$ is the thorium-uranium dioxide fuel density in $\mathrm{Kg} / \mathrm{m}^{3}$ and $\alpha$, is the mass fraction of $\mathrm{UO}_{2}$ in the oxide mixture.

The temperature dependence of specific heat and thermal conductivity in thorium-uranium dioxide fuel can be evaluated as in Eqs. (7-8).

$$
\begin{aligned}
& c_{p_{(T h, U) O_{2}}}=\alpha c_{p_{U O_{2}}}(1-\alpha) c_{p_{T h O_{2}}} \\
& \lambda_{(T h, U) O_{2}}=\alpha \lambda_{U O_{2}}+(1-\alpha) \lambda_{\text {ThO }_{2}}
\end{aligned}
$$

Temperature dependence of specific heat and thermal conductivity in $\mathrm{UO}_{2}$ and $\mathrm{ThO}_{2}$ can be calculated independently with the following equations in Eqs. (9-12) [13]:

$$
\begin{aligned}
& c_{p_{U O_{2}}}=52.1743+87.951 t-84.2411 t^{2}+ \\
& 31.542 t^{3}-2.6334 t^{4}-0.71391 t^{-2}\left[\frac{J}{m o l K}\right]
\end{aligned}
$$




$$
\begin{gathered}
c_{p_{\mathrm{ThO}_{2}}}=52.9620+0.05126 \mathrm{~T}- \\
3.6802 \cdot 10^{-5} T^{2}+9.2245 \cdot 10^{-9} T^{3}- \\
5.7403 T^{-2}\left[\frac{\mathrm{J}}{\mathrm{molK}}\right] \\
\lambda_{U O_{2}}=\frac{100}{7.5408+17.692 t+3.6142 t^{2}}+ \\
\frac{6400}{t^{\frac{5}{2}}} \exp \left\{\frac{-16.35}{t}\right\}\left[\frac{W}{m K}\right] \\
\lambda_{\mathrm{ThO}_{2}}=\frac{1}{-0.0464+2.5185 \cdot 10^{-4} T}\left[\frac{\mathrm{W}}{\mathrm{mK}}\right]
\end{gathered}
$$

\section{RESULTS AND DISCUSSION}

The convergence of the neutronic/thermalhydraulic coupled calculations was reached when the maximum relative deviation was less than $1 \%$ between the values of volumetric power density profiles from two consecutive iterations.

The iterative neutronic/thermal-hydraulic coupled calculations finished in the iteration 10 in both cases of study. The infinite coefficient of neutron multiplication $\left(\mathrm{k}_{\mathrm{inf}}\right)$ was calculated with a relative deviation less than $1 \%$. The iterative process showed a convergent behavior, as seen in Fig. 4.

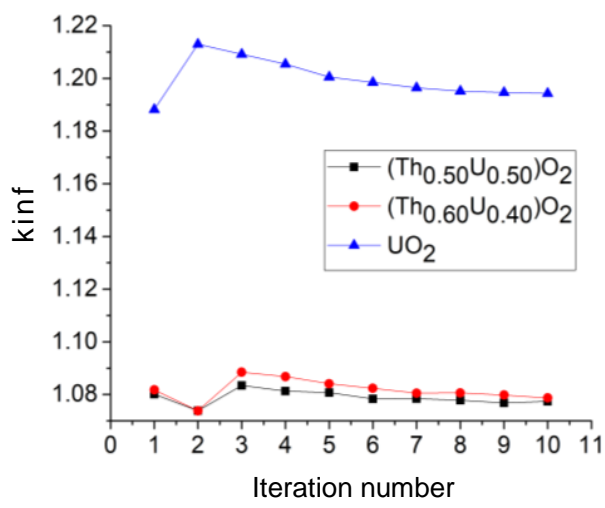

Fig. 4. Variation of $\mathrm{k}_{\mathrm{inf}}$ coefficient during the iterative process of the coupled calculation.

At the end of the coupled calculation, an infinite multiplication coefficient value of $1.07740 \pm 0.00018$ was obtained when using $\left(\mathrm{Th}_{0.50} \mathrm{U}_{0.50}\right) \mathrm{O}_{2}$ fuel and $1.07981 \pm 0.00018$ with $\left(\mathrm{Th}_{0.60} \mathrm{U}_{0.40}\right) \mathrm{O}_{2}$ fuel. In the analyzed fuel assembly design, neither burnable absorbers nor control rods were considered to balance the initial excess reactivity.

As fertile material, the ${ }^{232} \mathrm{Th}$ produces a lower contribution to core multiplicative properties than ${ }^{238} \mathrm{U}$. The above is due to the values of the cross sections of each isotope, mainly because the absorption cross section of ${ }^{232} \mathrm{Th}$ at thermal energies is three times that of ${ }^{238} \mathrm{U}$. For this reason, when thorium uranium dioxide is used, a considerable decrease in the infinite multiplication coefficient is observed compared to conventional fuel. In this study, a difference of approximately 12,000 pcm was obtained.

Table 5 compares for each case of study the percentage of fissions caused by thermal, intermediate and fast neutrons. As can be observed, fissions are mainly caused by neutrons with energies below $0.625 \mathrm{eV}$, so the present design of the HPLWR core can be considered as a thermal reactor with a hard spectrum. Furthermore, there are no notable changes in the neutron spectrum if the mass fraction of $\mathrm{ThO}_{2}$ is slightly varied.

Table 5: Percentage of fissions produced by thermal, intermediate and fast neutrons.

\begin{tabular}{ccc}
\hline \multirow{2}{*}{ Energy range } & \multicolumn{2}{c}{ \% of fissions } \\
\cline { 2 - 3 } & Case 1 & Case 2 \\
\hline $0 \mathrm{eV}-0.625 \mathrm{eV}$ & 72.98 & 72.59 \\
$0.625 \mathrm{eV}-0.1 \mathrm{MeV}$ & 20.95 & 21.77 \\
$>0.1 \mathrm{MeV}$ & 6.08 & 5.64 \\
\hline
\end{tabular}

Figure 5 shows the axial profiles of the average volumetric power for the cases studied and when using conventional fuel at BOC. The axial profiles of average volumetric power density for the two proposed fuels do not differ too much, with a maximum relative deviation is $4 \%$. The shape of the axial power distributions is similar when using $\mathrm{ThO}_{2}+\mathrm{UO}_{2}$ and $\mathrm{UO}_{2}$, but the maximum values obtained in the lower half of the fuel assembly are higher when thorium uranium dioxide fuels are used. At height of approximately $0.1 \mathrm{~m}$, the largest deviation is observed between the profiles of the two cases studied and the $\mathrm{UO}_{2}$. The difference is 323.21 MW/m $\mathrm{m}^{3}$, approximately.

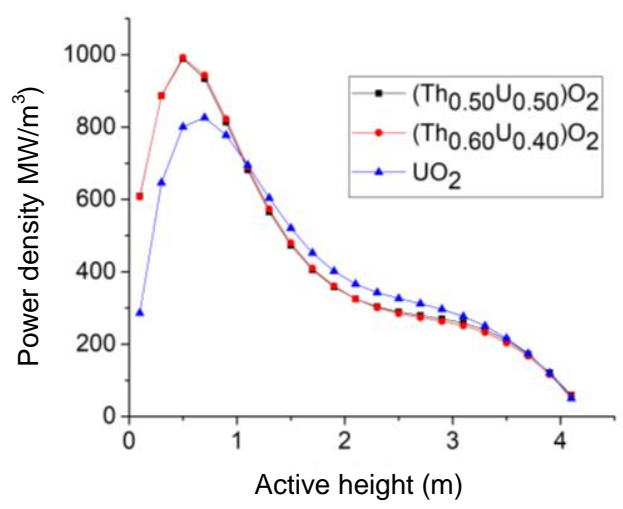

Fig. 5. The axial profiles of average volumetric power density in HPLWR fuel assembly.

The axial profiles of the volumetric power density in the fuel rods considered in the eighth of 
the fuel assembly are shown in Fig 6. In the radial direction, the power distribution is relatively uniform. The behavior of axial energy release is similar for the two cases studied. In rods 5 and 7, the minimum values are obtained. This is because the ${ }^{235} \mathrm{U}$ enrichment is smaller in the fuel rod number 7. In addition, fuel rod 5 is the furthest from the moderating zones.

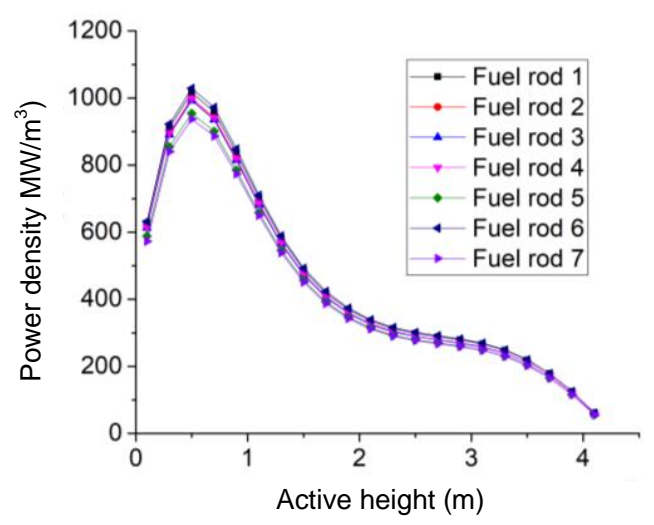

(a)

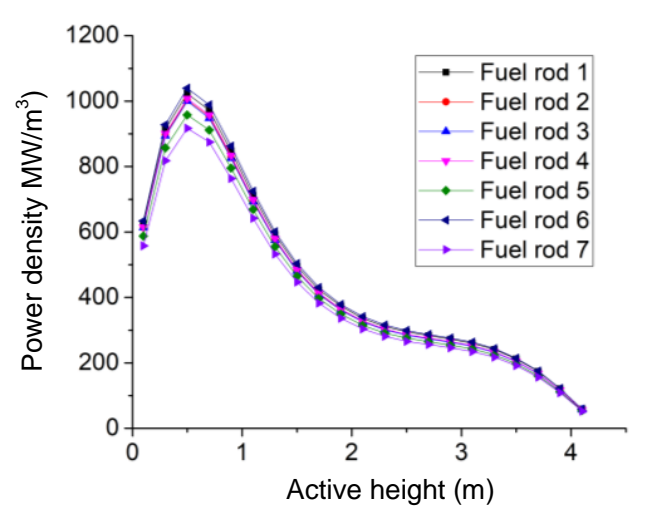

(b)

Fig 6. Axial distributions of the volumetric power density in the fuel rods, (a) $\left(\mathrm{Th}_{0.50} \mathrm{U}_{0.50}\right) \mathrm{O}_{2}$, (b) $\left(\mathrm{Th}_{0.60} \mathrm{U}_{0.40}\right) \mathrm{O}_{2}$.

The largest difference between rods with the highest and lowest energy release is $91.92 \mathrm{MW} / \mathrm{m}^{3}$ if using $\left(\mathrm{Th}_{0.50} \mathrm{U}_{0.50}\right) \mathrm{O}_{2}$ fuel and $122.26 \mathrm{MW} / \mathrm{m}^{3}$ if $\left(\mathrm{Th}_{0.60} \mathrm{U}_{0.40}\right) \mathrm{O}_{2}$ fuel is used. Fuel rod No. 6 shows the maximum absolute values of power density.

The axial profiles of the volumetric power density in the fuel rods using $\mathrm{ThO}_{2}+\mathrm{UO}_{2}$ fuels have similar behavior than obtained using $\mathrm{UO}_{2}$ fuel and published in [9].

Using $\left(\mathrm{Th}_{0.50} \mathrm{U}_{0.50}\right) \mathrm{O}_{2}$ fuel the coolant reaches outlet average temperature of $770.34 \mathrm{~K}$, while with $\left(\mathrm{Th}_{0.60} \mathrm{U}_{0.40}\right) \mathrm{O}_{2}$ fuel was $771.09 \mathrm{~K}$. Both are not far off to each other and to the design value in HPLWR (773.15 K).

The axial profiles of water temperature, considering coolant, internal and external moderator, are shown in Fig. 7. It can be observed the axial profiles of water temperatures do not change for the cases studied, and they change little compared to $\mathrm{UO}_{2}$ fuel, relative deviations less than $2 \%$ were obtained.

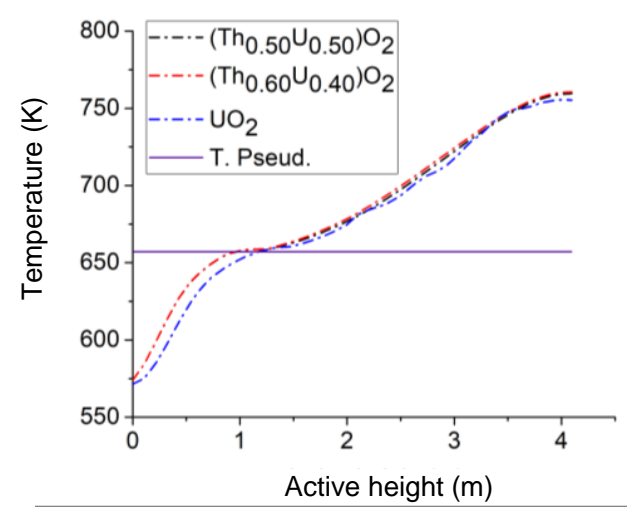

(a)

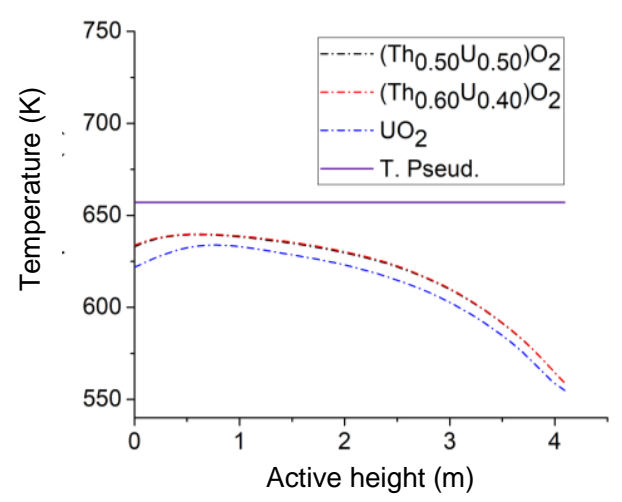

(b)

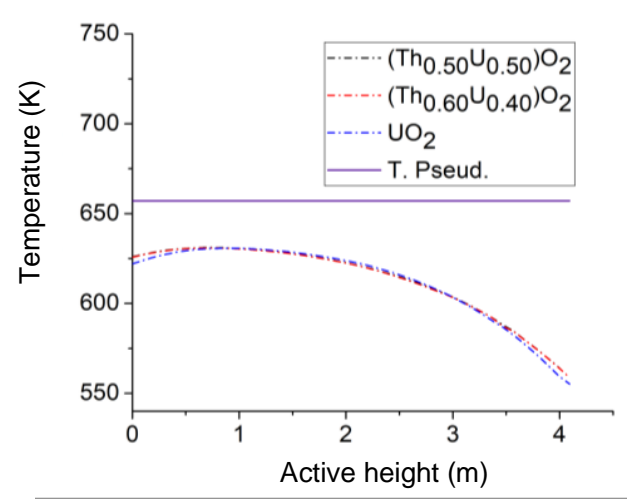

(c)

Fig. 7. Water temperature axial distributions, (a) coolant, (b) internal moderator, (c) external moderator.

The temperature increase when the coolant rises up the channel and reaches the pseudocritical point $(657.15 \mathrm{~K})$ at an approximate height of $1 \mathrm{~m}$. The moderator water heats up in the downward direction due to heat transfer with the coolant through the box walls, although the pseudo critical point is obviously not reached. The internal moderator temperature increases for $85 \mathrm{~K}$ and external moderator for $77 \mathrm{~K}$. The aforementioned temperatures may be justified by the lower thickness of the wall of the inner box. 
In the lower half of the fuel assembly, larger coolant heating occurs when thorium-based fuels are used. The above is due to the fact that in this area the volumetric power density values are higher than those obtained if the $\mathrm{UO}_{2}$ is used. The external moderator temperature profile is practically the same in all cases. The internal moderator gets hotter when using thorium fuels. This may be a consequence of increased heating of the coolant, which implies a higher temperature gradient between the coolant and the internal moderator.

The coolant temperature radial distribution at outlet of fuel assembly are shown in Fig. 8. The maximum temperature values are reached in the assembly central regions, where the fuel rods are close to each other and there is no heat exchange with the moderators. In the interior subchannels, temperature values lower than those in the rest of the subchannels are obtained, that is due to the heat transfer between the coolant and the internal moderator. The coolant minimum temperature values are achieved around rod number 3 , as there is a greater area of heat transfer with the internal moderator. In case 1, slightly higher coolant temperatures are obtained at the assembly outlet than in case 2.

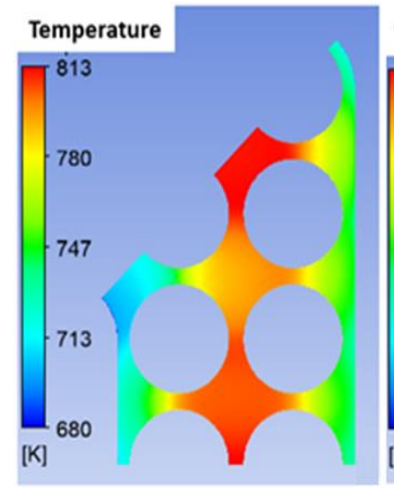

(a)

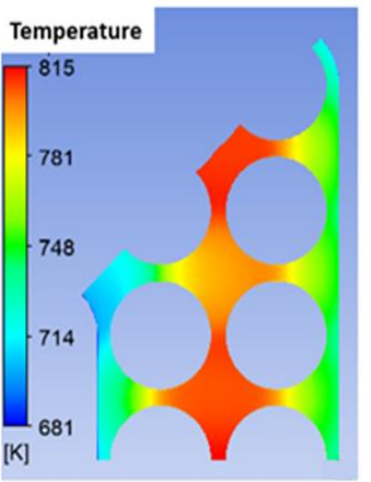

(b)
Fig. 8. Coolant temperature radial distribution at outlet of fuel assembly, (a) $\left(\mathrm{Th}_{0.50} \mathrm{U}_{0.50}\right) \mathrm{O}_{2}$, (b) $\left(\mathrm{Th}_{0.60} \mathrm{U}_{0.40}\right) \mathrm{O}_{2}$.

Figure 9 shows the axial profiles of coolant density at fuel assembly when the coupled calculation converged. The shape of the profiles does not differ much between thorium-based fuels and $\mathrm{UO}_{2}$. Faster decrease in coolant density occurs for thorium-based fuels, due to higher power density in the lower region of the assembly. The coolant density decreases from $741 \mathrm{~kg} / \mathrm{m}^{3}$ at the inlet of subchannels to $83 \mathrm{~kg} / \mathrm{m}^{3}$ at the core exit.

The following expression was used to calculate the weighted average temperature in the fuel rods, where $T_{c}$ is the temperature in the central line of the fuel rods and $T_{S}$, the temperature at the surface.

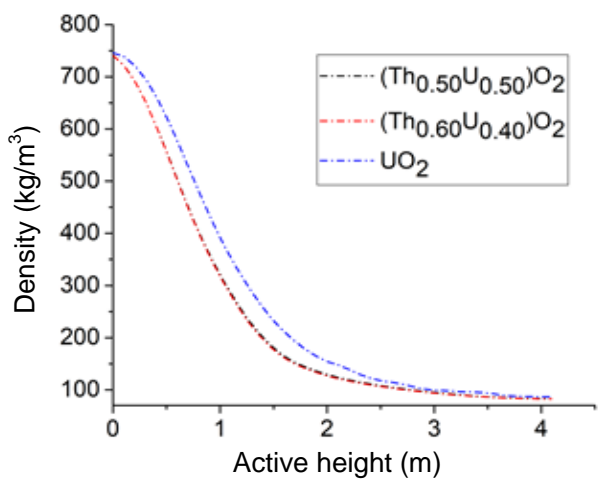

Fig. 9. The axial profiles of coolant density.

$$
T_{p}=\frac{4}{9} T_{c}+\frac{5}{9} T_{S}
$$

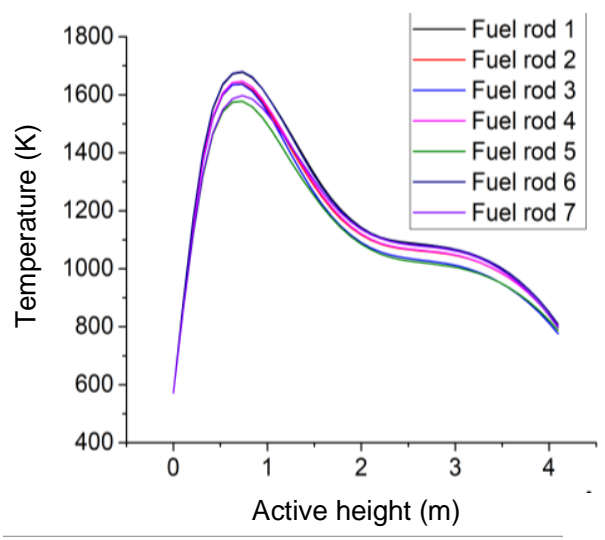

(a)

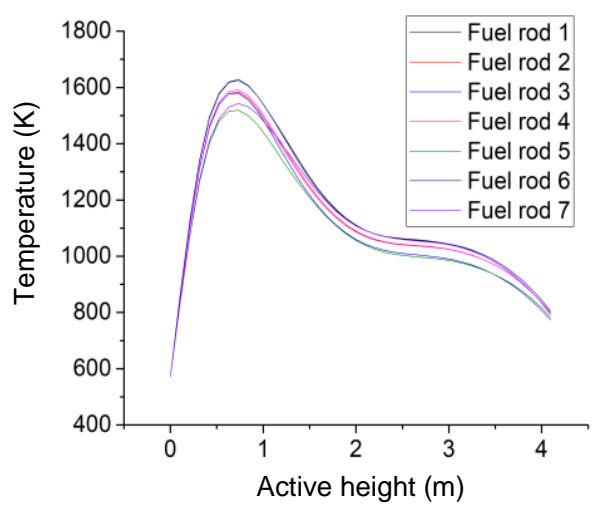

(b)

Fig. 10. The weighted temperature axial distributions, (a) $\mathrm{UO}_{2}$, (b) $\left(\mathrm{Th}_{0.50} \mathrm{U}_{0.50}\right) \mathrm{O}_{2}$.

The weighted temperature axial distributions in the fuel rods for $\mathrm{UO}_{2}$ and $\left(\mathrm{Th}_{0.50} \mathrm{U}_{0.50}\right) \mathrm{O}_{2}$ are shown in Fig. 10. The highest value of the weighted temperature in the fuel rods is reached in the region of maximum heat release, that is, in the lower area of the fuel assembly, at an approximate height of $0.74 \mathrm{~m}$. The rod number 6 reaches $1680 \mathrm{~K}$ using 
$\mathrm{UO}_{2}$ fuel, $1636 \mathrm{~K}$ using $\left(\mathrm{Th}_{0.50} \mathrm{U}_{0.50}\right) \mathrm{O}_{2}$ and $1627 \mathrm{~K}$ with $\left(\mathrm{Th}_{0.60} \mathrm{U}_{0.40}\right) \mathrm{O}_{2}$. The maximum value of the weighted temperature decreases slightly with the increase of the thorium mass fraction in the mixture, due to the better thermal conductivity of $\mathrm{ThO}_{2}$ compared to $\mathrm{UO}_{2}$.

Figure 11 shows the central line temperature axial profile of fuel rod number 6 . In the lower region, where the maximum values are reached, a decrease of up to $136 \mathrm{~K}$ is obtained for thoriumbased fuels. In the upper region, there are no notable differences, because here the power density distributions match. The thermal conductivity values of fuels $\left(\mathrm{Th}_{0.50} \mathrm{U}_{0.50}\right) \mathrm{O}_{2}$ and $\left(\mathrm{Th}_{0.60} \mathrm{U}_{0.40}\right) \mathrm{O}_{2}$ are very close to each other, so the temperature differences in the central line of rod number 6 are not appreciable. The axial temperature profiles in the central line of the rest of the fuel rods have a shape similar to that of rod number 6 .

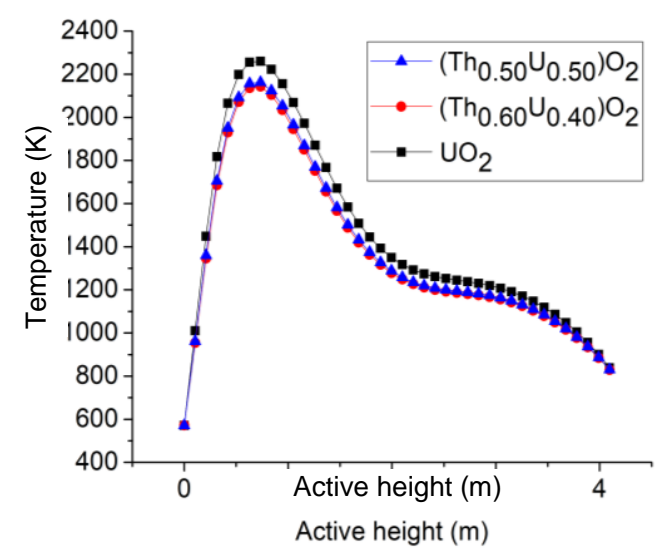

Fig. 11. Central line temperature axial profile of fuel rod number 6 .

The fuel temperature radial distributions at height of $0.74 \mathrm{~m}$ is shown in Fig. 12. In rods number 3 and 5 the lower values are obtained, due to its proximity to the interior moderator box, where the water drops with a lower temperature. The rod number 6 is the hottest, followed by number 1 , because despite its proximity to the interior moderator box, these rods achieve the highest power density values. When standard $\mathrm{UO}_{2}$ fuel is used, maximum fuel temperature of up to $2260 \mathrm{~K}$ are obtained. The use of the mixtures of oxides proposed as alternative fuels contributes to the decrease of the maximum temperature values in the fuel rods of HPLWR fuel assembly, by producing a greater heat transfer as a result of the higher thermal conductivity of $\mathrm{ThO}_{2}$. Using $\mathrm{UO}_{2}+\mathrm{THO}_{2}$, maximum fuel temperature values of $2163 \mathrm{~K}$ $\left.\left(\mathrm{Th}_{0.50} \mathrm{U}_{0.50}\right) \mathrm{O}_{2}\right)$, were obtained, which are much lower than the melting temperatures of $\mathrm{UO}_{2}$ $(3120 \mathrm{~K})$ and $\mathrm{ThO}_{2}(3651 \mathrm{~K})$.
The results show that it is possible to use thorium-based fuels in the form of mixture of thorium and uranium oxides with sufficient safety margins in the normal operation of the HPLWR reactor.

\section{CONCLUSION}

Homogeneous mixture of thorium and uranium oxides proposed as alternative fuels produce values of the neutron multiplication coefficient in the no poison core at BOC lower than standard $\mathrm{UO}_{2}$ fuel, even while maintaining the same initial mass of fissile isotope. This is due to the lower contribution of ${ }^{232} \mathrm{Th}$ to the multiplicative properties in the thermal neutronic spectrum.

The neutron spectrum of the HPLWR core does not vary considerably if the mass fraction of thorium in the mixture fuel is slightly modified.

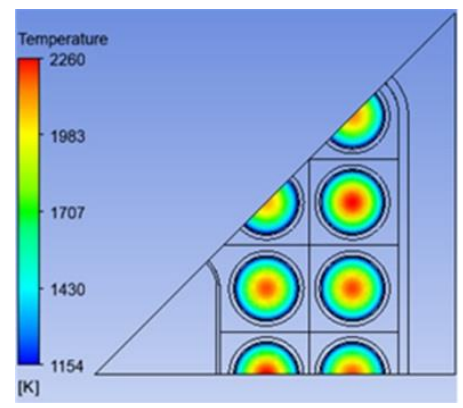

(a)

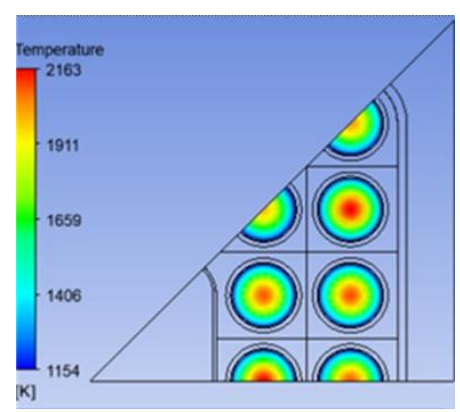

(b)

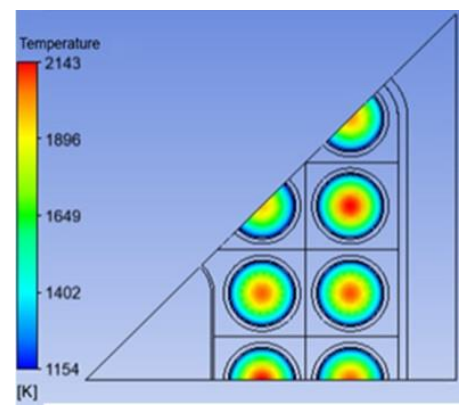

(c)

Fig. 12. Temperature radial distributions in fuel rods at height of $0.74 \mathrm{~m}$, (a) $\mathrm{UO}_{2}$, (b) $\left(\mathrm{Th}_{0.50} \mathrm{U}_{0.50}\right) \mathrm{O}_{2}$, (c) $\left(\mathrm{Th}_{0.60} \mathrm{U}_{0.40}\right) \mathrm{O}_{2}$. 
The average volumetric axial power density distributions in the typical fuel assembly of HPLWR are practically the same for the two cases studied and differ between them by less than $4 \%$. In both cases, maximum power density values of approximately $990 \mathrm{MW} / \mathrm{m}^{3}$ were obtained at a height of approximately $0.5 \mathrm{~m}$. These values are slightly higher than those previously obtained using $\mathrm{UO}_{2}$.

The coolant heats up on its way up the subchannels of the fuel assembly, reaching the pseudocritical point at height of $1 \mathrm{~m}$ in the both cases studied. Subchannel number 3 is the coldest and number 7 is the hottest. The temperature of the moderators increases as they descend through the fuel assembly, due to the heat exchange with the coolant through the walls of the boxes. The use of the proposed oxide mixtures produces little variation in the main thermal-hydraulic properties of the coolant and moderator of the HPLWR fuel assembly compared to when $\mathrm{UO}_{2}$ is used.

A significant decrease was obtained in the weighted average temperature values and in the central line temperature values of the HPLWR fuel rods, compared to standard $\mathrm{UO}_{2}$ fuel. These results allow the reactor operation with broader safety margins. Therefore, it was demonstrated that according the studied parameters, the homogeneous configurations of thorium and uranium dioxide mixtures can be used as alternative nuclear fuels in the HPLWR.

In general, the use of homogeneous mixtures of thorium and uranium dioxides is limited by the need to increase the ${ }^{235} \mathrm{U}$ enrichment of the $\mathrm{UO}_{2}$ in the mixture, in order to achieve burnup values similar to those achieved only with $\mathrm{UO}_{2}$.

Although the necessary ${ }^{235} \mathrm{U}$ enrichment values are lower than those allowed in LEU fuel, the amount of natural uranium required to form the thorium and uranium mixture fuel shall not be much less than that required to form the same amount of standard $\mathrm{UO}_{2}$. This is why thorium-based fuels that use homogeneous mixtures will be more advantageous when manufactured from reprocessed fuel and use ${ }^{233} \mathrm{U}$ or ${ }^{239} \mathrm{Pu}$ as fissile material.

\section{ACKNOWLEDGMENT}

The authors acknowledge the "Universidad Nacional Autónoma de México" for the postdoctoral fellowships of Landy Castro, for the support through the project PAP1IT-IN115517 and for facilitating the use of the MIZTLI supercomputer under the LANCAD-UNAMDGTIC-253 project.

\section{AUTHOR CONTRIBUTION}

Y. Pérez: Methodology, Investigation, Review and editing. C. R. García: Conceptualization, Methodology, Validation, Writing. F. L. Mena: Methodology, Validation, Review and editing. L. Castro: Validation, Review and editing.

\section{REFERENCES}

1. L. Pioro, Handbook of Generation IV Nuclear Reactors, Woodhead Publishing Series in Energy (2016) 103.

2. L. Castro, J-L. François and C. García, Prog. Nucl. Energy 124 (2020) 103342.

3. J. R. Maiorino, F. D'Auria and R. Akbari-Jeyhouni, An Overview of Thorium Utilization in Nuclear Reactors and Fuel Cycles, Proceedings of the 12th International Conference of the Croatian Nuclear Society, Croatia (2018).

4. S. Krahn, A. Worrall, T. Ault et al., Development of Fuel Cycle Data Packages for Thorium Fuel Cycle Options, Project No. 135220, Nuclear Energy University Programs, US Departement Energy (2017).

5. K. S. Chaudri, W. Tian, G. Su et al., Prog. Nucl. Energy 68 (2013) 55.

6. G. Csom, T. Reiss, S. Fehér et al., Ann. Nucl. Energy 41 (2012) 67.

7. L. Castro, R. Alfonso, C. García et al., Int. J. Nucl. Energy Sci. Technol. 11 (2017) 229.

8. L. Castro, J-L François and C. García, Ann. Nucl. Energy (2020) 107312.

9. J. T. Goorley, M. R. James, T. E. Booth et al., Initial MCNP6 Release Overview - MCNP6 version 1.0, U.S. Department of Energy (2016).

10. Anonymous, Release ANSYS 19.0 Release Notes 1-132, ANSYS (2018).

11. Anonymous, The International Association for the Properties of Water and Steam, IAPWS. http://www.iapws.org/index.html.

Retrieved in March (2020).

12. L. Castro, G. Delgado, C. García et al., Ann. Nucl. Energy 127 (2019) 227.

13. Anonymous, Thermophysical Properties of Materials for Nuclear Engineering: A Tutorial and Collection of Data, IAEA. https://www-pub.iaea.org/MTCD/Publications/ PDF/IAEA-THPH_web.pdf. Retrieved in December (2019). 